\title{
Orta Karadeniz Bölgesi'nden Toplanan Kaldırayak (Trachystemon orientalis (L.) G. Don.) Genotiplerinin Morfolojik Karakterizasyonu
}

\author{
Mehtap Özbakır Özer ${ }^{1 \star} \quad$ Beyhan Kibar ${ }^{2}$ \\ ${ }^{1}$ Karadeniz Tarımsal Araştırma Enstitüsü, Samsun \\ Bolu Abant İzzet Baysal Üniversitesi, Ziraat ve Doğa Bilimleri Fakültesi, Bahçe Bitkileri Bölümü, Bolu
}

Geliş tarihi (Received): 17.05.2018 Kabul tarihi (Accepted): 19.07.2018

\section{Anahtar kelimeler: \\ Kaldırayak, Trachystemon orientalis, Orta Karadeniz Bölgesi, karakterizasyon}

\section{*Sorumlu yazar}

mehtap_ozbakir@hotmail.com
Özet. Bu araştırmada, Orta Karadeniz Bölgesi'nde doğal olarak yetişen, halk tarafından çeşitli şekillerde tüketilen kaldırayak genotiplerinin toplanması ve karakterizasyonu amaçlanmıştır. Sörvey ve arazi çalışmaları 2011 yılının ilkbahar döneminde (Nisan-Mayıs) başlamış olup Samsun, Ordu, Amasya ve Tokat illerinde yürütülmüştür. Genetik materyali toplama çalışmaları sonucunda 29 farklı kaldırayak genotipi toplanmış ve toplanan materyallerin morfolojik karakterizasyonu yapılmıştır. Kaldırayak genotiplerinde bitkinin dik büyümesi ve rizomlu olması ortak özellik olarak belirlenmiştir. Kaldırayak genotipleri arasında en uzun bitki boyu 55 LA 04 nolu genotipte $43.7 \mathrm{~cm}$ olarak ölçülmüştür. Yeşil renkli, tüylü ve genotiplere göre değişen oranlarda antosiyanine sahip olan kaldırayak genotiplerinde, gövde uzunluğunun 7.0-29.7 cm, gövde kalınlığının ise 2.0-5.5 mm arasında değiştiği tespit edilmiştir. Kaldırayak genotiplerinde yaprakların yeşil, tüylü, üçgen şeklinde ve uç kısımlarının da sivri olduğu, fakat yaprak uzunluğu ve genişliğinin genotiplere göre değişiklik gösterdiği saptanmıştır. En uzun yaprak boyu $22 \mathrm{~cm}$ ile 55 HA 04 nolu genotipte, en kısa yaprak boyu ise 52 UL 01 nolu genotipte 10 cm olarak ölçülmüştür. Orta büyüklükte, mor renkli güzel çiçeklere sahip olan kaldırayak genotiplerinde ilk çiçeklenme Mart ayının ilk haftasında gözlemlenmiştir. Kaldırayak materyallerinin Nisan ayında hasat olgunluğuna geldiği tespit edilmiştir. Kaldırayak tohumlarının, bütün genotiplerde oval ve siyah renkli olduğu belirlenmiştir. Bitkideki tohum miktarının $0.1-21.6 \mathrm{~g}$, genotiplerin bin tane ağırığının $1.6 \mathrm{~g}$ (55 ÇA 01) ile $4.2 \mathrm{~g}$ (52 AK 03) arasında değiştiği tespit edilmiştir. Çalışmada ayrıca en verimli genotipin 55 ÇA $03\left(934.5 \mathrm{~g} \mathrm{bitki}^{-1}\right)$ olduğu belirlenmiştir.

\section{Morphological Characterization of Kaldırayak (Trachystemon orientalis (L.) G. Don.) Genotypes Collected From Central Black Sea Region}

\begin{tabular}{|c|c|}
\hline $\begin{array}{l}\text { Keywords: } \\
\text { Kaldırayak, Trachystemon } \\
\text { orientalis, Central Black Sea } \\
\text { Region, characterization }\end{array}$ & 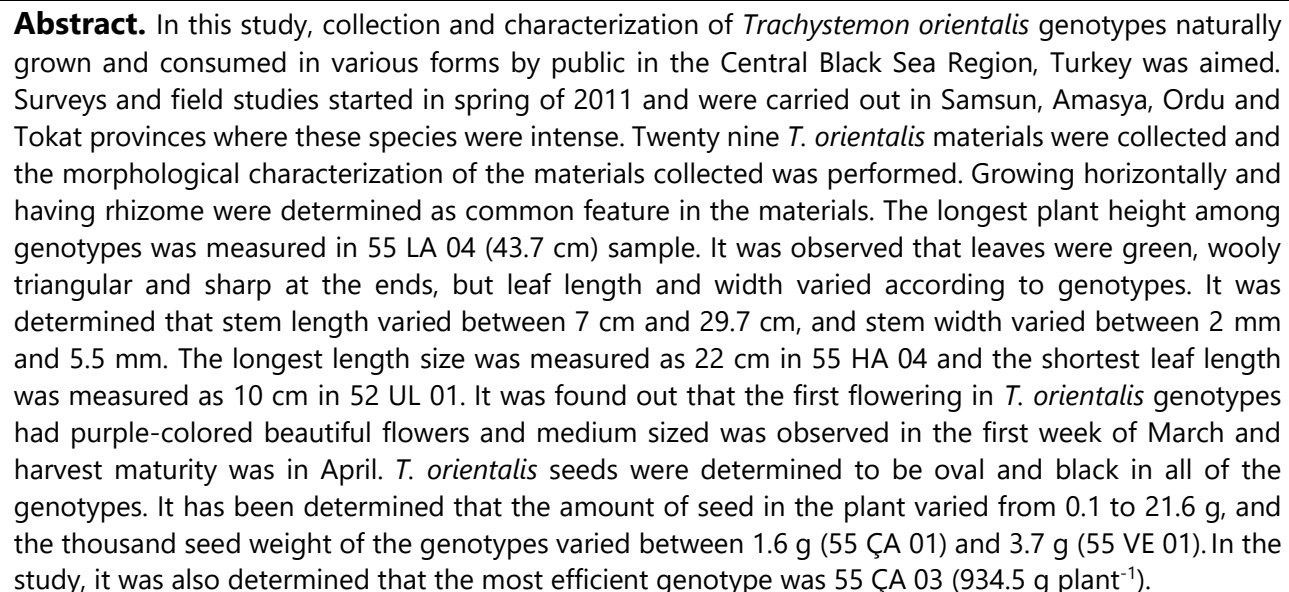 \\
\hline
\end{tabular}




\section{GiRiş}

Dünya nüfusunun hızla artması, insanların gereksinimlerini karşılamak amacıyla bitkisel kaynakların bilinçsizce kullanılması, arazi açmaları, yerel çeşitlerin yerini ıslah edilmiş yeni çeşitlerin almaya başlaması, yabancı ot ilaçlarının kullanımı, üretim yapmak yerine doğadan sökerek tüketme, tabii afetler, şehirleşme ve endüstrileşme bitki gen kaynaklarının azalmasına ve hızla kaybolmasına neden olmaktadır (Balkaya ve Yanmaz 2001; Özgen et al., 2004).

Değişen çevre koşullarına karşın hızla büyümekte olan dünya nüfusunun beslenmesi sorunu, genetik kaynakların önem ve değerini biraz daha arttırmaktadır (Karagöz et al., 2010). Son yıllarda tüm dünyada doğal beslenmeye doğru bir eğilim gelişmiştir. Bu eğilimin güç kazanması ile dikkatler doğada kendiliğinden yetişen kültüre alınmamış bitkilere de yönelmeye başlamıştır.

Özellikle yabani bitkilerin yapısında bulunan bazı maddelerin sağlık üzerindeki olumlu etkilerinin ortaya konulmasından sonra bu bitkiler giderek daha fazla ilgi çekmektedir. Bu türler sahip oldukları zengin mineral, vitamin ve lif içeriklerinden dolayı tüm dünyada olduğu gibi ülkemizde de çoğunlukla kullanılmaktadır. Özellikle kırsal kesimlerde yaşayan halk ekonomik nedenlerden dolayı bu türlerle yakından ilgilenmektedir. Onlar genellikle bu bitkilerin meyve, tohum, kabuk, yaprak, yumru gibi kısımlarını kullanmaktadırlar (Aksakal ve Kaya 2008). Halkın, sebze çeşitlerinin azaldığı ve turfanda olduğu aylarda, sebze ihtiyaçlarını mevcut yabani yenilebilir bitkilerden temin etmesi nedeniyle pazarlarda, manavlarda ve marketlerde bu bitkilerin satışında da artış olmaya başlamıştır.

Ülkemizde, 3607'si endemik olmak üzere 11.707 bitki taksonu bulunmaktadır (Güner et al., 2012). Bu tür zenginliği içerisinde, ülkemizde doğada kendiliğinden yetişen otsu bitkilerin sebze olarak tüketimi oldukça yaygındır (Karagöz et al., 2010; Kibar and Temel 2015). Ancak, tarımı yapılmayan ve iç piyasada tüketilen bu bitkiler doğal floradan toplanmaktadır. Doğal bitki toplamalarının yoğunlaşması floraya büyük zarar vermekte, doğal vejetasyonun bozulması ve bitki türlerinin yok olmasının yanı sıra erozyonun artmasına da neden olmaktadır. Bu yabani bitki türlerinin üretilerek kullanılması, bitki genetik kaynaklarının devamlılığını sağlama yönünden üzerinde durulması gereken önemli bir konudur.

Bölgelerde iklim koşullarına göre adapte olmuş farklı özelliklere sahip bitki türleri bulunmaktadır.
Karadeniz Bölgesi, yabani yenilebilir bitkiler bakımından Türkiye'nin yüksek potansiyele sahip bölgelerinden biridir (Doğan et al., 2004). Bölge yaygın el değmemiş alanları ile doğadaki bitki çeşitliliğini ve bunların tüketim kültürünü devam ettiren sayılı bölgelerimizdendir ve bu yabani bitkiler halkın beslenmesinde önemli bir kaynak oluşturmaktadır. Özellikle sebzelerin az olduğu ilkbahar aylarında havaların ısınmasıyla ortaya çıkan bu yabani bitkiler, kırsal kesimde yaşayan insanlar tarafından toplanarak bölgedeki yerel pazarlarda satılmaktadır. Bu bitkiler arasında yer alan kaldırayak (Trachystemon orientalis (L.) G. Don.) Boraginaceae familyasına ait rizomlu çok yıllık bir bitkidir. Bitki 30-40 cm uzunluğunda olup mavi-mor renkli çiçeklere ve büyük yapraklara sahiptir. Yöresel olarak "Kaldırayak, Hodan, Ispıt, Kaldırık, Kaldirik, Kalduruk, Balıkotu, Acı Hodan ve Doğu Hodanı" gibi isimlerle adlandırımaktadır. Genellikle Türkiye'nin Karadeniz Bölgesi'nde yayılış göstermektedir (Akçin et al., 2004). Bitkinin yaprakları, yaprak sapları, çiçekleri ve sürgünleri sebze olarak tükertilmektedir. Ayrıca bitki tibbi özelliklere de sahiptir (Köse et al., 2010).

Sebze olarak değerlendirilen yabani bitki türleriyle ilgili çalışmalar, genellikle sebze ıslahı alanı dışında çalışan diğer araştırıcılar tarafından yapılmaktadır. Botanikçiler, çevre bilimciler, coğrafyacılar, diyetisyenler, tıp uzmanları ve sosyologlar tarafından bu yenilebilen yabani bitki türlerinin besin maddesi içerikleri, tıbbi ve gıda amaçlı kullanımları yönünden araştırmalar yürütülmüştür. Bu bitki türleri, sebze ıslahı alanında çalışan araştırıcılar için önemli bir genetik kaynak niteliğindedir. Bununla birlikte, ülkemizde yabani bitkilerin toplanması, muhafazası, karakterizasyonu ve değerlendirilmesine yönelik olarak yapılmış çalışma sayısı çok azdır.

Bu çalışma ile Orta Karadeniz Bölgesi'nde doğal olarak yetişen, halk tarafından çeşitli şekillerde sevilerek tüketilen kaldırayak genotiplerinin toplanması ve morfolojik karakterizasyonlarının yapılması amaçlanmıştır.

\section{MATERYAL VE METOT}

Bu çalışma, 2011-2014 yılları arasında yapılmıştır. Araştırmanın sörvey çalışmaları, 2011 yılının NisanMayıs aylarında Samsun, Ordu, Amasya ve Tokat'da yürütülmüştür. Toplanan genetik materyallerin karakterizasyon çalışmaları ise Karadeniz Tarımsal Araştırma Enstitüsü'nde yapılmıştır. 
Materyal olarak Samsun, Ordu, Amasya ve Tokat'ta sebze olarak değerlendirilen kaldırayak popülasyonları kullanılmıştır. Genetik materyali toplama çalışmaları 2011 yılı ilkbahar döneminde (Nisan-Mayıs) yapılmıştır. Mümkün olabildiğince değişik ekolojik ve coğrafi alanlardan örnek alınabilmesi hususu dikkate alınarak, Samsun (Bafra, Çarşamba, Vezirköprü, Ladik, Havza), Ordu (Merkez ilçe, Akkuş, Ünye, Ulubey, Perşembe), Amasya (Merkez ilçe, Merzifon, Göynücek, Suluova, Taşova) ve Tokat (Merkez ilçe, Reşadiye, Niksar, Turhal ve Erbaa) illerinden 5'er adet ilçe belirlenmiştir. Toplama çalışmalarında 'gayeli örnekleme' yöntemi kullanılmıştır (Balkaya et al., 2008). Çalışmada 29 adet kaldırayak (Trachystemon orientalis) genotipi toplanmışır. Kaldırayak genotiplerinin toplandığı lokasyonlar ve GPS değerleri Çizelge 1'de ayrıntılı olarak sunulmuştur. Araştırmada gen kaynağı olarak toplanan bitki örnekleri plaka sistemi ile isimlendirilmiştir (Balkaya and Ergün 2007).

Toplama sırasında bitkinin botanik ve yöresel adı, toplama tarihi, durak numarası, duraktaki örnek numarası, yer, enlem, boylam ve rakım, habitat ve kaynağı, eğim, bakı, toprak, birlikte bulunduğu diğer türler, materyal tipi ve durumu, bolluk ve diğer tanımlayıcı notlar kaydedilmiştir. Bu konuda Ege Tarımsal Araştırma Enstitüsü'nün Toplama Formundan da yararlanılmıştır. Bitkilerin doğal ortamı ve morfolojik özellikleri ile ilgili bilgiler kaydedilerek gerekli arazi değerlendirmeleri yapılmış ve fotoğrafları çekilmiştir. Bitkilerin botanik olarak teşhislerinde Flora of Turkey (Davis 1967; Davis 1978)'den yararlanılmıştır. Amaca uygun bitkiler topraklı olarak sökülerek saksılara dikilmiş ve Karadeniz Tarımsal Araştırma Enstitüsü arazisine getirilmiştir. Toplanan populasyonlar ile gözlem bahçesi oluşturulmuştur.

Daha sonra arazide sıra arası ve sıra üzeri $30^{\prime} \mathrm{ar} \mathrm{cm}$ olmak üzere, $1.5 \mathrm{~m}^{\prime}$ lik sıralara dikilmiş ve $2.25 \mathrm{~m}^{2}$ lik $(1.5 \times 1.5 \mathrm{~m})$ parsellerde her genotipin bitki dikimi yapılmıştır. Parseller arasındaki mesafe $1 \mathrm{~m}$ bırakılmıştır. Bitkilerin sulama, gübreleme, yabancı ot temizliği vb. bakım işlemleri düzenli olarak yapılmıştır. Kaldırayak türüne ait UPOV ve IPGRI tanımlama katalogları henüz oluşturulmamıştır. Bu nedenle morfolojik karakterizasyon kriterleri Önen et al. (2010)'e göre belirlenmiştir. Morfolojik karakterizasyonda toplam 27 adet özellik incelenmiştir.

Çizelge 1. Kaldırayak genotiplerinin toplandığı lokasyonlar ve GPS değerleri. Table 1. Locations and GPS values where kaldırayak genotypes were collected.

\begin{tabular}{|c|c|c|c|c|c|}
\hline \multirow{2}{*}{$\begin{array}{l}\text { Örnek } \\
\text { Kod No }\end{array}$} & \multirow{2}{*}{$\begin{array}{l}\text { Bulunduğu Adres } \\
\text { (il, İlçe, Köy/Mahalle, Yetiştiği yer) }\end{array}$} & \multirow{2}{*}{$\begin{array}{l}\text { Toplama } \\
\text { tarihi }\end{array}$} & \multicolumn{3}{|c|}{ GPS Değerleri } \\
\hline & & & $\begin{array}{l}\text { Enlem } \\
\text { (Kuzey) }\end{array}$ & $\begin{array}{l}\text { Boylam } \\
\text { (Doğu) }\end{array}$ & $\begin{array}{c}\text { Yükseklik } \\
\text { (m) }\end{array}$ \\
\hline 55BA01 & SAMSUN-Bafra, Evrenuşağı, Orman & 13.04 .2011 & $41^{\circ} 30^{\prime} 180^{\prime \prime} \mathrm{K}$ & $35^{\circ} 57^{\prime} 684^{\prime \prime} \mathrm{D}$ & 88 \\
\hline 55BA02 & SAMSUN-Bafra, Köseli, Orman & 13.04 .2011 & $41^{\circ} 28^{\prime} 617^{\prime \prime} \mathrm{K}$ & $35^{\circ} 57^{\prime} 922^{\prime \prime} \mathrm{D}$ & 99 \\
\hline 55BA03 & SAMSUN-Bafra, Sürmeli, Dere kenarı & 13.04 .2011 & $41^{\circ} 28^{\prime} 220^{\prime \prime} \mathrm{K}$ & $35^{\circ} 56^{\prime} 570^{\prime \prime} \mathrm{D}$ & 83 \\
\hline 55BA04 & SAMSUN-Bafra, Uluağaç, Orman & 13.04 .2011 & $41^{\circ} 26^{\prime} 620^{\prime \prime} \mathrm{K}$ & $35^{\circ} 58^{\prime} 920^{\prime \prime} \mathrm{D}$ & 190 \\
\hline 55ÇA01 & SAMSUN- Çarşamba, Karaağaç, Fındık bahçesi & 08.04 .2011 & $41^{\circ} 12^{\prime} 200^{\prime \prime} \mathrm{K}$ & $36^{\circ} 47.555^{\prime \prime} \mathrm{D}$ & 20 \\
\hline 55ÇA02 & SAMSUN-Çarşamba, Acıklı, Fındık bahçesi & 08.04 .2011 & $41^{\circ} 12^{\prime} 427^{\prime \prime} \mathrm{K}$ & $36^{\circ} 46^{\prime} 717^{\prime \prime} \mathrm{D}$ & 19 \\
\hline 55ÇA03 & SAMSUN-Çarşamba, Yukarı Dikencik, Fındık bahçesi & 08.04 .2011 & $41^{\circ} 15^{\prime} 183^{\prime \prime} \mathrm{K}$ & $36^{\circ} 40^{\prime} 681^{\prime \prime} \mathrm{D}$ & 13 \\
\hline 55ÇA04 & SAMSUN-Çarşamba, Durakbaşı, Fındık bahçesi & 08.04 .2011 & $41^{\circ} 16^{\prime} 733^{\prime \prime} \mathrm{K}$ & $36^{\circ} 39^{\prime} 749^{\prime \prime} \mathrm{D}$ & 9 \\
\hline $55 \mathrm{HA} 01$ & SAMSUN-Havza, Kale, Ev bahçesi & 19.04.2011 & $41^{\circ} 03^{\prime} 304^{\prime \prime} \mathrm{K}$ & $35^{\circ} 46^{\prime} 617^{\prime \prime} \mathrm{D}$ & 629 \\
\hline $55 \mathrm{HA} 02$ & SAMSUN-Havza, Çamyatağı, Ev bahçesi & 19.04 .2011 & $41^{\circ} 06^{\prime} 053^{\prime \prime} \mathrm{K}$ & $35^{\circ} 48^{\prime} 527^{\prime \prime} \mathrm{D}$ & 732 \\
\hline $55 \mathrm{HA} 03$ & SAMSUN- Havza, Çamyatağı, Orman & 19.04.2011 & $41^{\circ} 07^{\prime} 226^{\prime \prime} \mathrm{K}$ & $35^{\circ} 50^{\prime} 385^{\prime \prime} \mathrm{D}$ & 938 \\
\hline $55 \mathrm{HA} 04$ & SAMSUN-Havza, Sıralı, Orman & 19.04.2011 & $41^{\circ} 07^{\prime} 420^{\prime \prime} \mathrm{K}$ & $35^{\circ} 53^{\prime} 575^{\prime \prime} \mathrm{D}$ & 1016 \\
\hline 55LA01 & SAMSUN-Ladik, Ahmetsaray, Ev bahçesi & 15.04 .2011 & $40^{\circ} 59^{\prime} 480^{\prime \prime} \mathrm{K}$ & $35^{\circ} 52^{\prime} 420^{\prime \prime} \mathrm{D}$ & 763 \\
\hline 55LA02 & SAMSUN-Ladik, Çadırkaya, Ev bahçesi & 15.04 .2011 & $40^{\circ} 59^{\prime} 320^{\prime \prime} \mathrm{K}$ & $35^{\circ} 50^{\prime} 455^{\prime \prime} \mathrm{D}$ & 743 \\
\hline 55LA03 & SAMSUN-Ladik, Başlamış, Ev bahçesi & 15.04 .2011 & $40^{\circ} 58^{\prime} 215^{\prime \prime} \mathrm{K}$ & $35^{\circ} 51^{\prime} 127^{\prime \prime} \mathrm{D}$ & 825 \\
\hline 55LA04 & SAMSUN-Ladik, Aşağı Gölyazı, Orman & 15.04 .2011 & $40^{\circ} 54^{\prime} 666^{\prime \prime} \mathrm{K}$ & $35^{\circ} 57^{\prime} 188^{\prime \prime} \mathrm{D}$ & 916 \\
\hline 55VE01 & SAMSUN-Vezirköprü, Pazarcı, Ev bahçesi & 21.04.2011 & $41^{\circ} 04^{\prime} 106^{\prime \prime} \mathrm{K}$ & $35^{\circ} 30^{\prime} 281^{\prime \prime} \mathrm{D}$ & 680 \\
\hline 55VE02 & SAMSUN-Vezirköprü, Kuyumcu, Ev bahçesi & 21.04.2011 & $41^{\circ} 13^{\prime} 315^{\prime \prime} \mathrm{K}$ & $35^{\circ} 39^{\prime} 345^{\prime \prime} \mathrm{D}$ & 939 \\
\hline 55VE03 & SAMSUN-Vezirköprü, Devalan, Ev bahçesi & 21.04.2011 & $41^{\circ} 15^{\prime} 074^{\prime \prime} \mathrm{K}$ & $35^{\circ} 39^{\prime} 492^{\prime \prime} \mathrm{D}$ & 923 \\
\hline 52AK01 & ORDU-Akkuş, Esentepe, Yol kenarı & 09.05 .2011 & $40^{\circ} 52^{\prime} 489^{\prime \prime} \mathrm{K}$ & $37^{\circ} 03^{\prime} 521^{\prime \prime} \mathrm{D}$ & 1124 \\
\hline 52AK02 & ORDU-Akkuş, Yenikonak, Orman & 09.05 .2011 & $40^{\circ} 51^{\prime} 117^{\prime \prime} \mathrm{K}$ & $37^{\circ} 06^{\prime} 326^{\prime \prime} \mathrm{D}$ & 942 \\
\hline 52АK03 & ORDU-Akkuş, Ormancık, Ev bahçesi & 09.05 .2011 & $40^{\circ} 49^{\prime} 155^{\prime \prime} \mathrm{K}$ & $36^{\circ} 58^{\prime} 621^{\prime \prime} \mathrm{D}$ & 1095 \\
\hline 52Mi01 & ORDU-Merkez, Kumbaşı Mahallesi, Fındık bahçesi & 10.05 .2011 & $41^{\circ} 00^{\prime} 498^{\prime \prime} \mathrm{K}$ & $37^{\circ} 51^{\prime} 336^{\prime \prime} \mathrm{D}$ & 63 \\
\hline 52PE01 & ORDU-Perşembe, Medreseönü, Yol kenarı & 10.05 .2011 & $41^{\circ} 04^{\prime} 445^{\prime \prime} \mathrm{K}$ & $37^{\circ} 37^{\prime} 415^{\prime \prime} \mathrm{D}$ & 28 \\
\hline 52PE02 & ORDU-Perşembe, Okçulu, Orman & 10.05 .2011 & $41^{\circ} 05^{\prime} 385^{\prime \prime} \mathrm{K}$ & $37^{\circ} 38^{\prime} 850^{\prime \prime} \mathrm{D}$ & 135 \\
\hline 52UL01 & ORDU-Ulubey, İlçe Merkezi, Yol kenarı & 10.05.2011 & $40^{\circ} 52^{\prime} 202^{\prime \prime} \mathrm{K}$ & $37^{\circ} 45^{\prime} 208^{\prime \prime} \mathrm{D}$ & 589 \\
\hline $52 U ̈ N 01$ & ORDU-Ünye, Ortaköy, Fındık bahçesi & 09.05 .2011 & $40^{\circ} 53^{\prime} 116^{\prime \prime} \mathrm{K}$ & $37^{\circ} 09^{\prime} 175^{\prime \prime} \mathrm{D}$ & 648 \\
\hline 52 ÜN02 & ORDU-Ünye, Yeşilkent, Fındık bahçesi & 09.05 .2011 & $41^{\circ} 00^{\prime} 446^{\prime \prime} \mathrm{K}$ & $37^{\circ} 14^{\prime} 258^{\prime \prime} \mathrm{D}$ & 164 \\
\hline 60RE01 & TOKAT-Reşadiye, Bozçalı, Ev bahçesi & 27.04.2011 & $40^{\circ} 32^{\prime} 583^{\prime \prime} \mathrm{K}$ & $37^{\circ} 17^{\prime} 680^{\prime \prime} \mathrm{D}$ & 1321 \\
\hline
\end{tabular}


Özbakır Özer ve Kibar, Orta Karadeniz Bölgesi'nden Toplanan Kaldırayak (Trachystemon orientalis (L.) G. Don.) Genotiplerinin Morfolojik Karakterizasyonu

\section{BULGULAR VE TARTIŞMA}

Sebze olarak değerlendirilen kaldırayak materyallerini toplama çalışmaları sonucunda; 29 farklı kaldırayak genotipi toplanmış, yapılan tür teşhisi sonucunda da genotipler arasında farklı tür olmadığı, hepsinin Trachystemon orientalis olduğu belirlenmiştir. Edmondson (1978), Türkiyede Boraginaceae familyasına ait tek bir türün $T$. orientalis (L.) G.Don. olduğunu bildirmiştir. Sörvey çalışmalarında sadece Amasya ilinde bu türe rastlanılmamış olup materyaller diğer il ve ilçelerden toplanmıştır.

Kaldırayak genotiplerinde bitkinin dik büyümesi ve rizomlu olması ortak özellik olarak belirlenmiştir. Bitki boyu, gövde uzunluğu, gövde kalınlığı, yaprak uzunluğu ve yaprak genişliği gibi özelliklerin genotiplere göre değiştiği saptanmıştır. Kaldırayak genotipleri arasında en uzun bitki boyu 55 LA 04 nolu genotipte $43.7 \mathrm{~cm}$ olarak ölçülmüştür. Bunun dışında 52 PE $02(43.0 \mathrm{~cm}), 55$ ÇA $03(42.0 \mathrm{~cm})$ ve 52 PE 01 $(41.8 \mathrm{~cm})$ nolu genotiplerde bitki boyu yüksek bulunmuştur. Bununla birlikte, en düşük bitki boyuna sahip genotip 55 HA $03(18 \mathrm{~cm})$ olarak belirlenmiştir (Çizelge 2). Kaldırayak bitkisinin çok yıllık, rizomlu ve bitki boyunun 30-40 cm olduğu bildirilmiştir (Edmondson 1978; Baytop, 1984). Civelek (2011), Bafra Ovasında sebze olarak kullanılan yabani bitkileri incelediği çalışmada kaldırayakta bitki boyunu 34.75 $\mathrm{cm}$ olarak belirlemiştir.

Yeşil renkli, tüylü ve genotiplere göre değişen oranlarda antosiyanine sahip olan kaldırayaklarda gövde uzunluğunun 7.0-29.7 cm, gövde kalınlığının ise 2.0-5.5 mm arasında değiştiği tespit edilmiştir. En yüksek gövde uzunluğu 55 LA 04 genotipinde ölçülmüştür. Gövde uzunluğu yüksek diğer bir genotipte 52 PE $02(28 \mathrm{~cm})$ olarak tespit edilmiştir. En düşük gövde uzunluğu ise 55 HA 03 nolu genotipte belirlenmiştir (Çizelge 2).

Kaldırayaklarda yaprakların yeşil, tüylü, üçgen şeklinde ve uç kısımlarının da sivri olduğu fakat yaprak uzunluğu ve genişliğinin genotiplere göre değişiklik gösterdiği saptanmıştır (Şekil 1). En uzun yaprak boyu $22 \mathrm{~cm}$ ile 55 HA 04 nolu genotipte, en kısa yaprak boyu ise $10 \mathrm{~cm}$ ile 52 UL 01 nolu genotipte ölçülmüştür. Yaprak genişliği ise 8.7 (55 ÇA 02) ile $19.3 \mathrm{~cm}$ (55 HA 02) arasında değişmiştir (Çizelge 2). Civelek (2011), Bafra'da kaldırayakların yaprak boyunu $14.20 \mathrm{~cm}$, yaprak enini 11.97 cm; Demir ve ark. (2017), ise
Salıpazarı'ndaki kaldırayaklarda yaprak boyunu 14.32 $\mathrm{cm}$, yaprak enini ise $12.74 \mathrm{~cm}$ olarak belirlemişlerdir.

Orta büyüklükte mor renkli güzel çiçeklere sahip olan kaldırayaklarda ilk çiçeklenme Mart ayında gözlemlenmiştir (Şekil 2). Kaldırayak materyallerinin Nisan ayında hasat olgunluğuna geldiği tespit edilmiştir (Çizelge 2). Demir ve ark. (2017), Salıpazarı'nda da mor-mavi renkli çiçeklere sahip olan kaldırayakların Nisan ayında hasat edildiğini bildirmişlerdir.

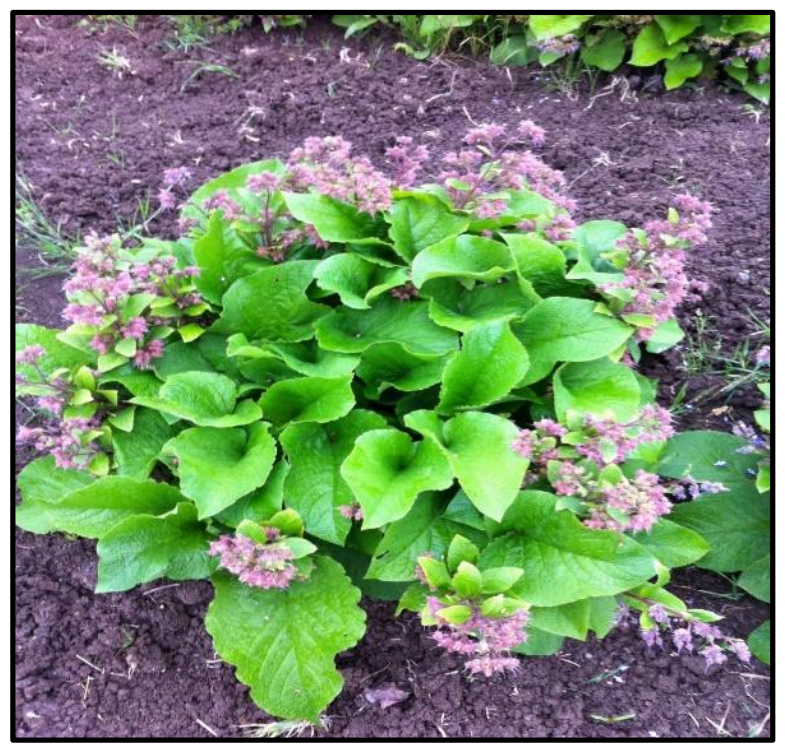

Şekil 1. Kaldırayak bitkisinin genel görünümü.

Figure 1. General appearance of kaldırayak plant.

Kaldırayak tohumlarının, bütün genotiplerde oval ve siyah renkli olduğu belirlenmiştir (Şekil 3). Bitkideki tohum miktarının $0.1 \mathrm{~g}$ ile $21.6 \mathrm{~g}$ arasında değiştiği ve en fazla tohum miktarının 55 LA 01 nolu genotipte gözlendiği belirlenmiş̧ir. Bitkideki tohum miktarının en az olduğu genotipler ise 55 VE 01, 55 ÇA $02,55 \mathrm{HA}$ 03 ve 55 LA 02 olarak bulunmuştur. Bin tane ağırlığı en fazla 52 AK 03 ( $4.2 \mathrm{~g})$ nolu genotipte, en düşük ise 55 ÇA 01 (1.6 g) nolu genotipte tespit edilmiştir (Çizelge 2).

Bitki çiçekli veya çiçeklenmenin hemen öncesinde yaprak saplarından kesilerek hasat edilmektedir. Bitkinin taze yaprakları, yaprak sapları ve çiçekleri tüketilmektedir. Bitkinin tüketilen kısımlarına göre değerlendirme yapıldığında hasat zamanında en verimli genotipin 55 ÇA 03 olduğu belirlenmiştir. Bu genotipte verimin $934.5 \mathrm{~g} \mathrm{bitki}^{-1}$ olduğu saptanmıştır. Buna karşılık, en düşük verime sahip genotip 55 HA 03 (27 $\mathrm{g} \mathrm{bitki}^{-1}$ ) olarak belirlenmiştir (Çizelge 2). 
Çizelge 2. Kaldırayak genotiplerinin morfolojik karakterizasyonu.

Table 2. Morphological characterization of kaldirayak genotypes.

\begin{tabular}{|c|c|c|c|c|c|c|c|c|c|c|}
\hline \multirow[t]{2}{*}{ Morfolojik özellik } & \multicolumn{10}{|c|}{ Genotip } \\
\hline & 55 BA 01 & 55 BA 02 & 55 BA 03 & 55 BA 04 & 55 ÇA 01 & 55 ÇA 02 & 55 ÇA 03 & 55 ÇA 04 & 55 HA 01 & 55 HA 02 \\
\hline Bitki boyu $(\mathrm{cm})$ & $32.3 \pm 0.24$ & $33.7 \pm 0.34$ & $37.5 \pm 0.31$ & $34.0 \pm 0.23$ & $34.7 \pm 0.28$ & $22.8 \pm 0.19$ & $42.0 \pm 0.35$ & $32.0 \pm 0.17$ & $35.0 \pm 0.19$ & $40.5 \pm 0.22$ \\
\hline Bitki duruşu & Dik & Dik & Dik & Dik & Dik & Dik & Dik & Dik & Dik & Dik \\
\hline Bitki gücü & Güçlü & Güçlü & Güçlü & Güçlü & Güçlü & Güçlü & Güçlü & Güçlü & Güçlü & Güçlü \\
\hline Rizom varlığı & Var & Var & Var & Var & Var & Var & Var & Var & Var & Var \\
\hline Gövde uzunluğu (cm) & $16.3 \pm 0.29$ & $19.0 \pm 0.16$ & $22.0 \pm 0.11$ & $18.0 \pm 0.25$ & $17.8 \pm 0.21$ & $13.0 \pm 0.20$ & $25.5 \pm 0.26$ & $13.5 \pm 0.19$ & $20.0 \pm 0.11$ & $23.8 \pm 0.22$ \\
\hline Gövde kalınlığı (mm) & $3.3 \pm 0.25$ & $3.6 \pm 0.24$ & $4.0 \pm 0.12$ & $3.7 \pm 0.17$ & $4.5 \pm 0.19$ & $2.4 \pm 0.21$ & $5.0 \pm 0.34$ & $5.04 \pm 0.20$ & $4.0 \pm 0.09$ & $4.0 \pm 0.29$ \\
\hline Gövde tüylülüğü & Yeşil & Yeşil & Yeşil & Yeşil & Yeşil & Yeşil & Yeşil & Yeşil & Yeşil & Yeşil \\
\hline Gövde rengi & Yeşil & Yeşil & Yeşil & Yeşil & Yeşil & Yeşil & Yeşil & Yeşil & Yeşil & Yeşil \\
\hline Antosiyanin oluşumu & Var & Var & Var & Var & $\mathrm{Az}$ & Var & Var & Var & Var & Var \\
\hline İlk çiçeklenme & 08.03.2012 & 08.03.2012 & 08.03 .2012 & 08.03 .2012 & 19.03 .2013 & 19.03 .2013 & 08.03 .2012 & 08.03.2012 & 19.03.2013 & 19.03.2013 \\
\hline \%50 çiçeklenme & 19.03.2013 & 19.03 .2013 & 19.03 .2013 & 21.03.2013 & 21.03 .2013 & 21.03 .2013 & 19.03 .2013 & 19.03 .2013 & 21.03 .2013 & 19.03.2013 \\
\hline Hasat olum zamanı & 02.04 .2013 & 02.04 .2013 & 02.04 .2013 & 02.04 .2013 & 02.04 .2013 & 02.04 .2013 & 02.04 .2013 & 02.04 .2013 & 02.04 .2013 & 02.04 .2013 \\
\hline Ömür uzunluğu & Çok yıllık & Çok yıllık & Çok yıllık & Çok yıllık & Çok yıllık & Çok yıllık & Çok yıllık & Çok yıllık & Çok yıllık & Çok yıllık \\
\hline Verim (g bitki $\left.{ }^{-1}\right)$ & $270 \pm 0.25$ & $408 \pm 0.22$ & $308 \pm 0.08$ & $242 \pm 0.08$ & $171 \pm 0.28$ & $96 \pm 0.16$ & $935 \pm 0.30$ & $230 \pm 0.15$ & $292 \pm 0.09$ & $263 \pm 0.21$ \\
\hline Yaprak uzunluğu (cm) & $15.8 \pm 0.26$ & $16.0 \pm 0.21$ & $15.5 \pm 0.16$ & $16.0 \pm 0.10$ & $17.2 \pm 0.12$ & $11.4 \pm 0.15$ & $21.0 \pm 0.27$ & $19 \pm 0.16$ & $14.0 \pm 0.25$ & $20.5 \pm 0.21$ \\
\hline Yaprak genişliği (cm) & $12.5 \pm 0.24$ & $12.0 \pm 0.23$ & $16.0 \pm 0.21$ & $14.0 \pm 0.21$ & $12.0 \pm 0.28$ & $8.7 \pm 0.10$ & $16.5 \pm 0.23$ & $16 \pm 0.11$ & $13.0 \pm 0.23$ & $19.3 \pm 0.24$ \\
\hline Yaprak rengi & Yeşil & Yeşil & Yeşil & Yeşil & Yeşil & Yeşil & Yeşil & Yeşil & Yeşil & Yeşil \\
\hline Yaprak şekli & Üçgenimsi & Üçgenimsi & Üçgenimsi & Üçgenimsi & Üçgenimsi & Üçgenimsi & Üçgenimsi & Üçgenimsi & Üçgenimsi & Üçgenimsi \\
\hline Yaprak uç şekli & Sivri & Sivri & Sivri & Sivri & Sivri & Sivri & Sivri & Sivri & Sivri & Sivri \\
\hline Yaprakta kabarıklııı & Yok & Yok & Yok & Yok & Yok & Yok & Yok & Yok & Yok & Yok \\
\hline Yaprak tüylülüğü & Var & Var & Var & Var & Var & Var & Var & Var & Var & Var \\
\hline Çiçek rengi & Mor & Mor & Mor & Mor & Mor & Mor & Mor & Mor & Mor & Mor \\
\hline Çiçek büyüklüğü & Orta & Orta & Orta & Orta & Orta & Orta & Orta & Orta & Orta & Orta \\
\hline Tohum rengi & Siyah & Siyah & Siyah & Siyah & Siyah & Siyah & Siyah & Siyah & Siyah & Siyah \\
\hline Tohum şekli & Oval & Oval & Oval & Oval & Oval & Oval & Oval & Oval & Oval & Oval \\
\hline Bitkideki tohum miktarı (g) & 9.2 & 7.4 & 5.6 & 1.1 & 10.6 & 0.1 & 3.7 & 0.4 & 2.9 & 5.3 \\
\hline 1000 tane ağırlığı (g) & 3.1 & 2.0 & 2.3 & 1.8 & 1.6 & 2.0 & 1.8 & 2.4 & 2.8 & 2.3 \\
\hline
\end{tabular}


Çizelge 2. Devamı

Table 2. Continue.

\begin{tabular}{|c|c|c|c|c|c|c|c|c|c|c|}
\hline \multirow[t]{2}{*}{ Morfolojik özellik } & \multicolumn{10}{|c|}{ Genotip } \\
\hline & 55 HA 03 & 55 HA 04 & 55 LA 01 & 55 LA 02 & 55 LA 03 & 55 LA 04 & 55 VE 01 & 55 VE 02 & 55 VE 03 & 52 UL 01 \\
\hline Bitki boyu $(\mathrm{cm})$ & $18.0 \pm 0.21$ & $37.0 \pm 0.15$ & $33.0 \pm 0.24$ & $25.5 \pm 0.23$ & $20.5 \pm 0.18$ & $43.7 \pm 0.23$ & $24.0 \pm 0.25$ & $33.0 \pm 0.22$ & $31.0 \pm 0.19$ & $24.3 \pm 0.19$ \\
\hline Bitki duruşu & Dik & Dik & Dik & Dik & Dik & Dik & Dik & Dik & Dik & Dik \\
\hline Bitki gücü & Güçlü & Güçlü & Güçlü & Güçlü & Güçlü & Güçlü & Güçlü & Güçlü & Güçlü & Güçlü \\
\hline Rizom varlığı & Var & Var & Var & Var & Var & Var & Var & Var & Var & Var \\
\hline Gövde uzunluğu (cm) & $7.0 \pm 0.22$ & $14.0 \pm 0.22$ & $14.5 \pm 0.18$ & $10.5 \pm 0.19$ & $9.0 \pm 0.20$ & $29.7 \pm 0.25$ & $11.0 \pm 0.15$ & $20.0 \pm 0.10$ & $13.0 \pm 0.16$ & $15.0 \pm 0.21$ \\
\hline Gövde kalınlığı (mm) & $2.8 \pm 0.23$ & $4.3 \pm 0.21$ & $3.0 \pm 0.26$ & $3.8 \pm 0.20$ & $3.0 \pm 0.21$ & $3.5 \pm 0.33$ & $2.0 \pm 0.32$ & $4.0 \pm 0.29$ & $2.7 \pm 0.31$ & $2.8 \pm 0.21$ \\
\hline Gövde tüylülüğü & Yeşil & Yeşil & Yeşil & Yeşil & Yeşil & Yeşil & Yeşil & Yeşil & Yeşil & Yeşil \\
\hline Gövde rengi & Yeşil & Yeşil & Yeşil & Yeşil & Yeşil & Yeşil & Yeşil & Yeşil & Yeşil & Yeşil \\
\hline Antosiyanin oluşumu & Var & $\mathrm{Az}$ & Var & Var & Var & Var & Var & Var & Var & Var \\
\hline İlk çiçeklenme & 21.03 .2013 & 19.03 .2013 & 19.03.2013 & 21.03.2013 & 21.03.2013 & 08.03 .2012 & 21.03 .2013 & 19.03 .2013 & 19.03 .2013 & 19.03.2013 \\
\hline \%50 çiçeklenme & 21.03 .2013 & 21.03 .2013 & 21.03 .2013 & 21.03 .2013 & 21.03 .2013 & 19.03 .2013 & 21.03 .2013 & 19.03.2013 & 21.03 .2013 & 21.03 .2013 \\
\hline Hasat olum zamanı & 02.04 .2013 & 02.04 .2013 & 02.04 .2013 & 02.04 .2013 & 02.04 .2013 & 02.04 .2013 & 02.04 .2013 & 02.04 .2013 & 02.04 .2013 & 02.04 .2013 \\
\hline Ömür uzunluğu & Çok yıllık & Çok yıllık & Çok yıllık & Çok yıllık & Çok yıllık & Çok yıllık & Çok yıllık & Çok yıllık & Çok yıllık & Çok yıllık \\
\hline Verim (g bitki $\left.{ }^{-1}\right)$ & $27 \pm 0.14$ & $217 \pm 0.19$ & $360 \pm 0.15$ & $48 \pm 0.15$ & $48 \pm 0.18$ & $609 \pm 0.32$ & $75 \pm 0.21$ & $139 \pm 0.10$ & $150 \pm 0.14$ & $105 \pm 0.15$ \\
\hline Yaprak uzunluğu (cm) & $11.5 \pm 0.11$ & $22.0 \pm 0.23$ & $17.0 \pm 0.10$ & $14.0 \pm 0.18$ & $12.7 \pm 0.18$ & $19.0 \pm 0.24$ & $14.0 \pm 0.10$ & $17.5 \pm 0.09$ & $14.0 \pm 0.21$ & $10.0 \pm 0.19$ \\
\hline Yaprak genişliği (cm) & $9.0 \pm 0.09$ & $17.0 \pm 0.19$ & $12.5 \pm 0.16$ & $12.0 \pm 0.10$ & $11.4 \pm 0.09$ & $16.7 \pm 0.24$ & $9.5 \pm 0.22$ & $15.3 \pm 0.10$ & $9.0 \pm 0.16$ & $9.2 \pm 0.12$ \\
\hline Yaprak rengi & Yeşil & Yeşil & Yeşil & Yeşil & Yeşil & Yeşil & Yeşil & Yeşil & Yeşil & Yeşil \\
\hline Yaprak şekli & Üçgenimsi & Üçgenimsi & Üçgenimsi & Üçgenimsi & Üçgenimsi & Üçgenimsi & Üçgenimsi & Üçgenimsi & Üçgenimsi & Üçgenimsi \\
\hline Yaprak uç şekli & Sivri & Sivri & Sivri & Sivri & Sivri & Sivri & Sivri & Sivri & Sivri & Sivri \\
\hline Yaprakta kabarıklılık & Yok & Yok & Yok & Yok & Yok & Yok & Yok & Yok & Yok & Yok \\
\hline Yaprak tüylülüğü & Var & Var & Var & Var & Var & Var & Var & Var & Var & Var \\
\hline Çiçek rengi & Mor & Mor & Mor & Mor & Mor & Mor & Mor & Mor & Mor & Mor \\
\hline Çiçek büyüklüğü & Orta & Orta & Orta & Orta & Orta & Orta & Orta & Orta & Orta & Orta \\
\hline Tohum rengi & Siyah & Siyah & Siyah & Siyah & Siyah & Siyah & Siyah & Siyah & Siyah & Siyah \\
\hline Tohum şekli & Oval & Oval & Oval & Oval & Oval & Oval & Oval & Oval & Oval & Oval \\
\hline Bitkideki tohum miktarı (g) & 0.1 & 3.2 & 21.6 & 0.1 & 1.1 & 14.7 & 0.1 & 1.5 & 0.4 & 0.7 \\
\hline 1000 tane ağırlığı (g) & 2.0 & 2.0 & 2.3 & 2.0 & 1.9 & 3.2 & 3.7 & 2.0 & 2.4 & 1.8 \\
\hline
\end{tabular}




\begin{tabular}{|c|c|c|c|c|c|c|c|c|c|}
\hline \multirow[t]{2}{*}{ Morfolojik özellik } & \multicolumn{9}{|c|}{ Genotip } \\
\hline & 52 PE 01 & 52 PE 02 & 52 Mi 01 & 52 ÜN 01 & 52 ÜN 02 & 52 АК 01 & 52 АК 02 & 52 AK 03 & 60 RE 01 \\
\hline Bitki boyu (cm) & $41.8 \pm 0.15$ & $43.0 \pm 0.26$ & $38.3 \pm 0.42$ & $30.0 \pm 0.30$ & $40.3 \pm 0.27$ & $37.3 \pm 0.28$ & $37.0 \pm 0.21$ & $37.3 \pm 0.28$ & $29.5 \pm 0.30$ \\
\hline Bitki duruşu & Dik & Dik & Dik & Dik & Dik & Dik & Dik & Dik & Dik \\
\hline Bitki gücü & Güçlü & Güçlü & Güçlü & Güçlü & Güçlü & Güçlü & Güçlü & Güçlü & Güçlü \\
\hline Rizom varlığı & Var & Var & Var & Var & Var & Var & Var & Var & Var \\
\hline Gövde uzunluğu (cm) & $23.8 \pm 0.24$ & $28.0 \pm 0.09$ & $23.7 \pm 0.23$ & $15.5 \pm 0.14$ & $22.3 \pm 0.20$ & $20.7 \pm 0.14$ & $18.0 \pm 0.15$ & $18.3 \pm 0.25$ & $15.0 \pm 0.15$ \\
\hline Gövde kalınlığı (mm) & $4.0 \pm 0.27$ & $4.0 \pm 0.15$ & $4.0 \pm 0.25$ & $3.0 \pm 0.15$ & $4.7 \pm 0.23$ & $5.2 \pm 0.11$ & $4.4 \pm 0.20$ & $5.6 \pm 0.25$ & $4.3 \pm 0.12$ \\
\hline Gövde tüylülüğü & Yeşil & Yeşil & Yeşil & Yeşil & Yeşil & Yeşil & Yeşil & Yeşil & Yeşil \\
\hline Gövde rengi & Yeşil & Yeşil & Yeşil & Yeşil & Yeşil & Yeşil & Yeşil & Yeşil & Yeşil \\
\hline Antosiyanin oluşumu & Var & Var & Var & Var & Var & Var & Var & Var & Var \\
\hline İlk çiçeklenme & 08.03 .2012 & 19.03 .2013 & 08.03 .2012 & 08.03 .2012 & 08.03 .2012 & 19.03 .2013 & 19.03 .2013 & 19.03.2013 & 19.03 .2013 \\
\hline \%50 çiçeklenme & 19.03.2013 & 19.03.2013 & 19.03.2013 & 19.03.2013 & 21.03.2013 & 19.03.2013 & 19.03.2013 & 21.03.2013 & 19.03.2013 \\
\hline Hasat olum zamanı & 02.04 .2013 & 02.04 .2013 & 02.04 .2013 & 02.04 .2013 & 02.04 .2013 & 02.04 .2013 & 02.04 .2013 & 02.04 .2013 & 02.04 .2013 \\
\hline Ömür varlığı & Çok yıllık & Çok yıllık & Çok yıllık & Çok yıllık & Çok yıllık & Çok yıllık & Çok yıllık & Çok yıllık & Çok yıllık \\
\hline Verim $\left(\mathrm{g} \mathrm{bitki} \mathrm{i}^{-1}\right)$ & $454 \pm 0.31$ & $281 \pm 0.15$ & $464 \pm 0.31$ & $236 \pm 0.11$ & $530 \pm 0.10$ & $179 \pm 0.10$ & $259 \pm 0.10$ & $214 \pm 0.10$ & $146 \pm 0.09$ \\
\hline Yaprak uzunluğu (cm) & $18.3 \pm 0.28$ & $15.0 \pm 0.20$ & $15.7 \pm 0.24$ & $13.0 \pm 0.19$ & $16.0 \pm 0.09$ & $17.5 \pm 0.20$ & $17.0 \pm 0.19$ & $19.0 \pm 0.20$ & $15.0 \pm 0.21$ \\
\hline Yaprak genişliği (cm) & $14.0 \pm 0.25$ & $12.5 \pm 0.22$ & $14.3 \pm 0.21$ & $10.3 \pm 0.19$ & $14.2 \pm 0.22$ & $17.3 \pm 0.19$ & $12.8 \pm 0.15$ & $15.7 \pm 0.29$ & $14.5 \pm 0.18$ \\
\hline Yaprak rengi & Yeşil & Yeşil & Yeşil & Yeşil & Yeşil & Yeşil & Yeşil & Yeşil & Yeşil \\
\hline $\begin{array}{l}\text { Yaprak şekli } \\
\text { Yaprak uç şekli }\end{array}$ & $\begin{array}{l}\text { Üçgenimsi } \\
\text { Sivri }\end{array}$ & $\begin{array}{l}\text { Üçgenimsi } \\
\text { Sivri }\end{array}$ & $\begin{array}{l}\text { Üçgenimsi } \\
\text { Sivri }\end{array}$ & $\begin{array}{l}\text { Üçgenimsi } \\
\text { Sivri }\end{array}$ & $\begin{array}{l}\text { Üçgenimsi } \\
\text { Sivri }\end{array}$ & $\begin{array}{l}\text { Üçgenimsi } \\
\text { Sivri }\end{array}$ & $\begin{array}{l}\text { Üçgenimsi } \\
\text { Sivri }\end{array}$ & $\begin{array}{l}\text { Üçgenimsi } \\
\text { Sivri }\end{array}$ & $\begin{array}{l}\text { Üçgenimsi } \\
\text { Sivri }\end{array}$ \\
\hline Yaprakta kabarıklılık & Yok & Yok & Yok & Yok & Yok & Yok & Yok & Yok & Yok \\
\hline Yaprak tüylülüğü & Var & Var & Var & Var & Var & Var & Var & Var & Var \\
\hline Çiçek rengi & Mor & Mor & Mor & Mor & Mor & Mor & Mor & Mor & Mor \\
\hline Çiçek büyüklüğü & Orta & Orta & Orta & Orta & Orta & Orta & Orta & Orta & Orta \\
\hline Tohum rengi & Siyah & Siyah & Siyah & Siyah & Siyah & Siyah & Siyah & Siyah & Siyah \\
\hline Tohum şekli & Oval & Oval & Oval & Oval & Oval & Oval & Oval & Oval & Oval \\
\hline Bitkideki tohum miktarı (g) & 14.5 & 9.4 & 8.6 & 1.1 & 10.3 & 2.3 & 3.6 & 3.7 & 3.2 \\
\hline 1000 tane ağırlığı (g) & 1.9 & 2.0 & 1.8 & 1.8 & 2.0 & 2.3 & 2.9 & 4.2 & 1.8 \\
\hline
\end{tabular}


Özbakır Özer ve Kibar, Orta Karadeniz Bölgesi'nden Toplanan Kaldırayak (Trachystemon orientalis (L.) G. Don.) Genotiplerinin Morfolojik Karakterizasyonu
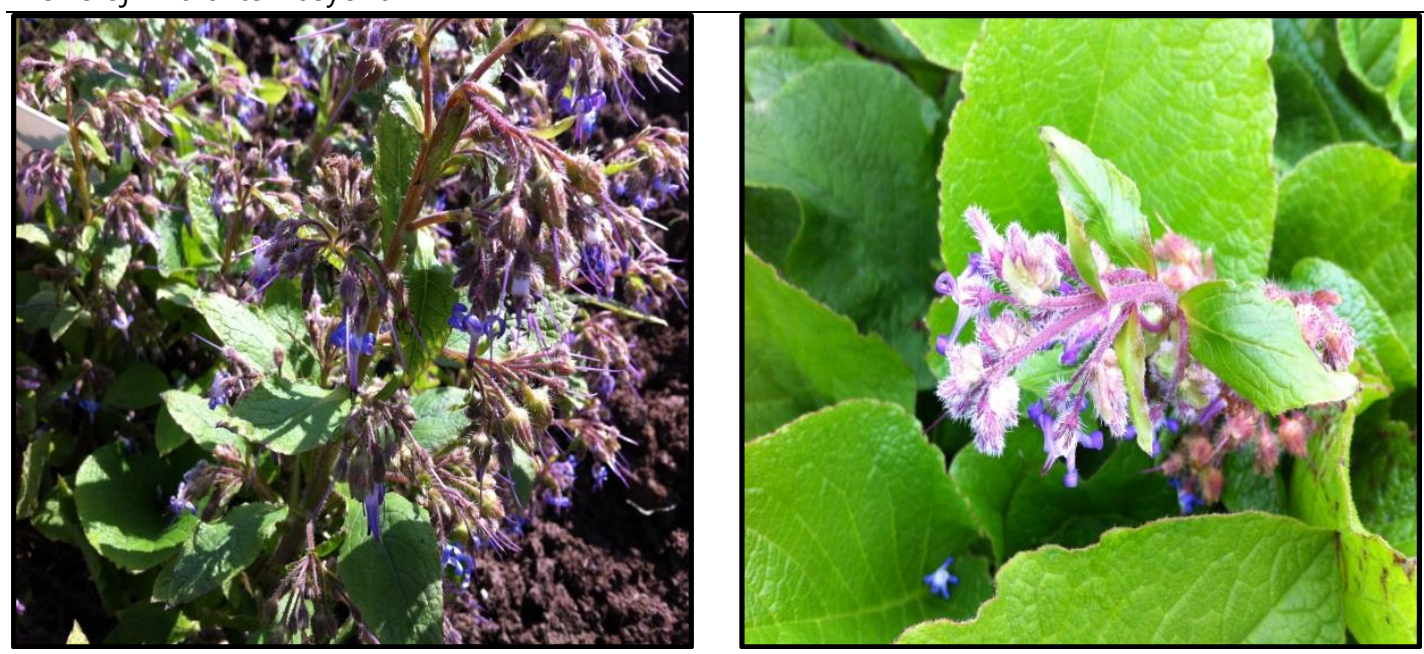

Şekil 2. Kaldırayak çiçeklerinin genel görünümü.

Figure 2. General appearance of kaldırayak flowers.
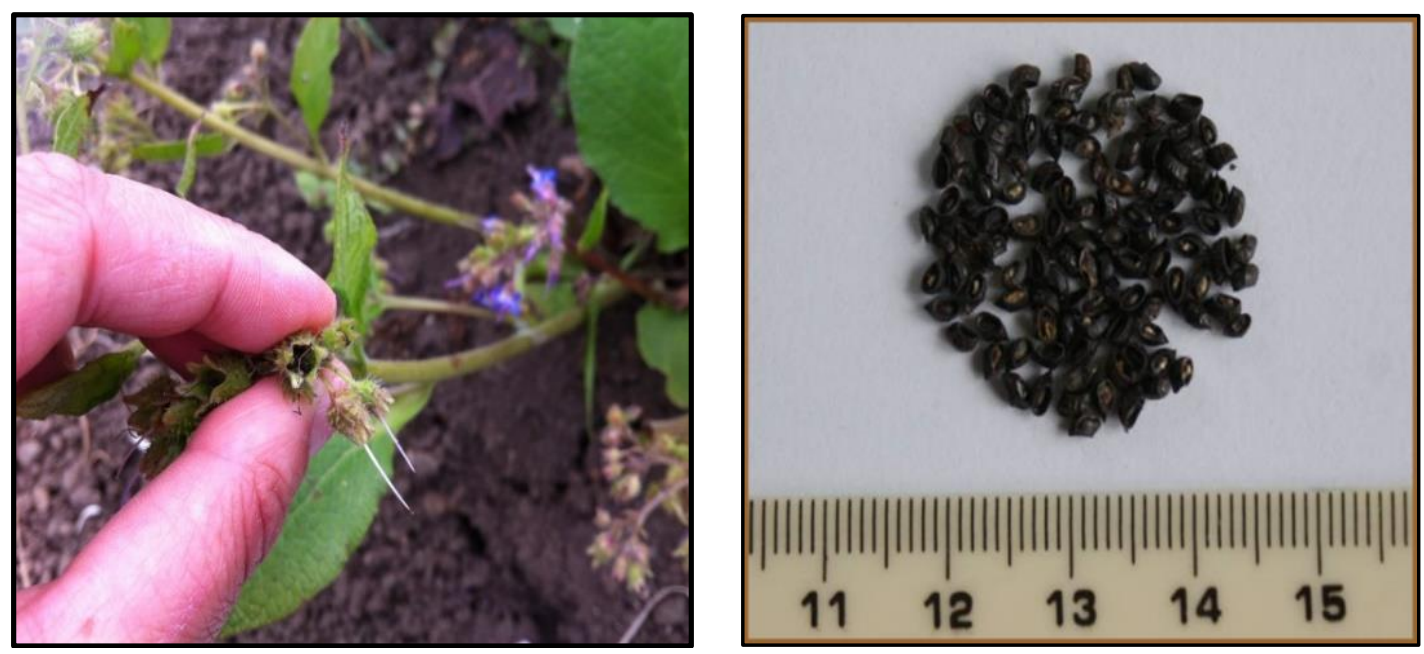

Şekil 3. Kaldırayak tohumlarının genel görünümü. Figure 3. General appearance of kaldirayak seeds.

\section{SONUÇ}

Dünyanın ve Türkiye'nin birçok bölgesinde olduğu gibi Orta Karadeniz Bölgesi'nde de yöre halkı, yabani bitki türlerine yoğun şekilde talep göstermekte ve besin kaynağı olarak farklı şekillerde değerlendirmektedir. Bu talebin nedenleri insanların artık doğal ve dengeli beslenmeyi istemeleri, yabani türlerin tıbbi özelliklerinin olduğunun bilinmesi ve de sebze olarak değerlendirilen yabani bitki türlerinin kültür sebzelerine göre daha farklı tat, lezzet ve aroma özelliklerine sahip olması olarak sıralanabilir. Bu nedenle, başta daha çok talep edilen bu türler olmak üzere diğer türlerin de kültüre alınabilme olanaklarının araştırılmasına yönelik çalışmalar daha fazla sayıda yapılmalıdır.

\section{TEŞEKKÜR}

Bu çalışma Tarımsal Araştırmalar ve Politikalar Genel Müdürlüğü (TAGEM/TA/11/06/01/009) tarafından desteklenmiştir.

\section{KAYNAKLAR}

Akçin ÖE., Kandemir $\mathrm{N}$ and Akçin Y., 2004. A morphological and anatomical study on a medicinal and edible plant Trachystemon orientalis (L.) G. Don (Boraginaceae) in the Black Sea Region. Turkish Journal of Botany, 28: 435-442.

Aksakal Ö ve Kaya Y., 2008. Erzurum ve Çevresinde Halk Tarafından Gıda Amaçlı Olarak Kullanılan Bitkiler. Türkiye 10. Gida Kongresi, 21-23 Mayıs, Erzurum.

Balkaya A ve Yanmaz R., 2001. Bitki genetik kaynaklarının muhafaza imkânları ve tohum gen bankalarının çalışma prensipleri. Çevre Koruma Dergisi, 10(39): 25-30. 
Özbakır Özer ve Kibar, Orta Karadeniz Bölgesi'nden Toplanan Kaldırayak (Trachystemon orientalis (L.) G. Don.) Genotiplerinin Morfolojik Karakterizasyonu

Balkaya A and Ergün A., 2007. Determination of Superior Pinto Bean Phaseolus vulgaris L var Pinto Genotypes By Selection Under The Ecological Conditions of Samsun Province in Turkey. Turkish Journal of Agriculture and Forestry, 31: 335-347.

Balkaya A., Kurtar ES and Yanmaz R., 2008. Evaluation and selection of suitable pumpkin Cucurbita moschata Duchense types from Turkey. Acta Horticulturae, 830(830): 55-62.

Baytop T., 1984. Türkiye'de Bitkiler ile Tedavi (Geçmişte ve Bugün). İstanbul Üniversitesi Eczacılık Fakültesi, İstanbul Üniversitesi Yayınları No: 3255, İstanbul.

Civelek C., 2011. Bafra Ovası'nda sebze olarak kullanılan yabani bitkilerin toplanması, bazı besin içeriklerinin saptanması ve ıslah amaçlı olarak değerlendirilmesi. Yüksek Lisans Tezi, Ondokuz Mayıs Üniversitesi Fen Bilimleri Enstitüsü, Samsun.

Davis PH., 1967. Flora of Turkey and the East Aegean Islands. Vol. 2, University of Edinburg, England.

Davis PH., 1978. Flora of Turkey and the East Aegean Islands. Vol 6, University of Edinburg, England.

Demir E., Yılmaz H., Özer H ve Kutbay HG., 2017. Samsun/Salıpazarı ilçesinde yayılış gösteren bazı yenilebilir yabani bitkilerin karakteristik özelliklerinin belirlenmesi üzerine araştırma. Mesleki Bilimler Dergisi, 6(3): 738-749.
Doğan Y., Baslar S., Ay G and Mert HH., 2004. The use of wild edible plants in Anatolia (Turkey). Economic Botany, 58: 684-690.

Edmondson JR., 1978. Trachystemon D. Don. Flora of Turkey and the East Aegean Islands (Ed. Davis PH), Edinburgh University Press, pp. 386-387.

Güner A., Aslan S., Ekim T., Vural M ve Babaç MT., 2012. Türkiye Bitkileri Listesi (Damarlı Bitkiler). Nezahat Gökyiğit Botanik Bahçesi ve Flora Araştırmaları Derneği Yayını, İstanbul.

Karagöz A., Zencirci N., Tan A., Taşkın T., Köksel H., Sürek M., Toker C ve Özbek K., 2010. Bitki genetik kaynaklarının korunması ve kullanımı. Türkiye Ziraat Mühendisliği VII. Teknik Kongresi, 11-15 Ocak, Ankara.

Kibar B and Temel S., 2015 Evaluation of Mineral composition of some wild edible plants growing in the eastern anatolia region grasslands of Turkey and consumed as vegetable. Journal of Food Processing and Preservation, 40: 56-66.

Köse YB., Güner ST., Malyer H and Demirci F., 2010. Elemental analyses of medicinal an food plant: Trachystemon orientalis (L.) G. Don. XIII OPTIMA Meeting, 22-26 March 2010, Antalya.

Özgen U., Kaya and Coşkun M., 2004. Ethnobotanical studies in the villages of the district of llıca (Province Erzurum), Turkey. Economic Botany, 58(4): 691-696. 